\title{
RISK FACTORS AND COMPLICATIONS OF SMALL FOR GESTATIONAL AGE (SGA) IN TERM NEWBORNS IN FIRST 24 HOURS AFTER DELIVERY.
}

\footnotetext{
1. MBBS, FCPS (Paeds Medicine) Senior Registrar Pediatric Medicine Nishtar Medical College \& Hospital, Multan

2. MBBS, FCPS (Paeds Medicine) Associate Professor Pediatric Medicine

Nishtar Medical College \& Hospital, Multan

3. MBBS, MPH

PGT MS (Paeds Surgery)

Nishtar Medical College \& Hospital, Multan

Correspondence Address:

Dr. Saima Jabeen Joiya

Senior Registrar Pediatric Medicine

Nishtar Medical College \& Hospital,

Multan.

zahidahmad78@gmail.com

Article received on:

04/02/2019

Accepted for publication:

03/07/2019
}

\section{Saima Jabeen Joiya1, Muhammad Azam Khan², Zahid Ahmad ${ }^{3}$}

ABTRACT... Objectives: To determine the frequency of risk factors and acute complications for SGA in term new borns during first 24 hours after delivery. Study Design: Descriptive Case Series. Setting: Department of Pediatric Medicine, Nishter Hospital, Multan. Period: 15 Aug 2014 to 30 Apr 2015. Material \& Methods: A total of 157 term babies, delivered in labor room in Nishter hospital Multan were evaluated in 24 hours of birth. Mother of each SGA baby was examined regarding history, clinical examination and nutritional status were noted. SGA babies were completely monitored for 24 hours in the department of pediatric medicine for complications. Results: There were 88 (56.1\%) male and 69 (43.9\%) female. Mean age and weight of the patients at the time of presentation were $12.73+6.65$ hours and $2.03+0.65$ $\mathrm{Kg}$ respectively. Among mothers, 61.1\% were nulliparous, anemia was found in $47.8 \%$, inter pregnancy intervals of less than or equal to one year in $58.6 \%$ and hypertension in $61.8 \%$. Among SGA babies, perinatal asphyxia was found to be present in $63.7 \%$, meconium aspiration in $51 \%$, hypothermia in $37.6 \%$, hypoglycemia in $24.2 \%$, hypocalcaemia in $32.5 \%$, polycythemia in $47.1 \%$ and thrombocytopenia in 41.4\%. Conclusion: Maternal hypertension, nulliparity, short inter pregnancy interval and anemia were frequently encountered risk factors for SGA babies. The most frequently encountered perinatal complications observed were perinatal asphyxia, meconium aspiration, polycythemia, thrombocytopenia, hypothermia, hypocalcaemia and hypoglycemia in decreasing order of frequency.

Key words: $\quad$ Meconium Aspiration, Nulliparity, Perinatal Asphyxia, SGA.

Article Citation: Joiya SJ, Khan MA, Ahmad Z. Risk factors and complications of small for gestational age (SGA) in term newborns in first 24 hours after delivery. Professional Med J 2020; 27(4):688-694.

DOI: 10.29309/TPMJ/2020.27.04.3219

\section{INTRODUCTION}

Many descriptive terms were proposed from time to time to characterize the group of infants who have impaired fetal growth; these include pseudo premature, small for dates, dysmature, and fetal malnourished, chronic fetal distress, intrauterine growth retardation (IUGR), hypotrophic and small for gestational age (SGA). ${ }^{1}$ Small for gestational age (SGA) has been defined as infant having birth weight less than $10^{\text {th }}$ centile for gestation. ${ }^{2}$

This definition includes infants whose birth weight is below the $10^{\text {th }}$ percentile due to fetal malnutrition or other intrauterine events, but it also includes infants who have reached their genetic growth potential, are normal, and happen to be lighter than $90 \%$ of the population. Every neonate should be compared with the population of similar social, ethinic and socioeconomic background. There are no present or old large population-based birth weight normograms available for Pakistani population. In Pakistan we used "Colorado growth chart" produced by Lubchencoet al. ${ }^{3}$ In Pakistan 10 - 25\% of newborn may be full term SGA and most are asymmetrical. ${ }^{4}$ The mortality rate for babies who are SGA and is nine times higher than those of Appropriate for Gestational Age (AGA) ${ }^{5}$

Causes of low birth weight are multifactorial with genetic, placental, fetal and maternal factors interplaying with each other. A strong correlation exists between birth weight and maternal height, weight, age, antenatal care visits and risk status at pregnancy. ${ }^{6}$ Malnourished mothers face potential complications in childbirth and the likelihood 
of low birth weight babies. ${ }^{7}$ More than $40 \%$ of Pakistani pregnant women are anemic and give birth to SGA babies. The incidence of low birth weight babies in these women is as high as $25 \%{ }^{8}$

A variety of acute perinatal events may occur in SGA infants. These infants are more vulnerable to perinatal complications which have harmful influences on subsequent growth and development. Among these are perinatal asphyxia, meconium aspiration syndrome, hypoglycemia, hypocalcaemia, pulmonary hemorrhage, hypothermia, polycythemia, thrombocytopenia and infections. ${ }^{9-11}$

There is paucity of data on this subject in Pakistani studies, so this study was planned to identify common risk factors in pregnant women resulting to the birth of SGA newborn. Study was also done to note acute complication in SGA newborn. So that based on these observations, recommendations could be made for the improvement of measures on preventive as well as on management sides to reduce morbidity and mortality in SGA newborns according to our resources and facilities.

\section{MATERIAL \& METHODS}

This was a descriptive case series study carried out at the Department of Pediatric Medicine, Nishtar Hospital, Multan, from 15 Aug 2014 to 30 Apr 2015.

Total 157 children during the study period were enrolled by using non- probability consecutive sampling. All full term newborns up to age of 24hours having weight less than $10^{\text {th }}$ centile \& gestation confirmed by ultrasonography with cephalic presentation of fetus were included in study. However twin babies, preterm SGA and dysmorphic babies were excluded.

Approval from ethical committee and an informed consent from the attendant were taken. All the term babies who were delivered in labor room in Nishter Hospital Multan were evaluated in 24 hours of birth. Birth weight was recorded in baby weight scale, gestational age was calculated by using ballard score. If baby fulfills the criteria then he/she was enrolled in study. Mother of each SGA baby was examined and her data was reviewed, complete history and examination was done. Obstetric history was obtained with special reference to age, parity, duration of gestation and interpregnancy interval from mother. Nutritional status of mother, any previous SGA baby, history of hypertension and record during pregnancy was checked. All enrolled SGA babies were completely monitored for $24 \mathrm{hrs}$ in department of pediatric medicine and noted for any complications especially perinatal asphyxia (deprivation of oxygen to a newborn infant that lasted long enough during the birth process to cause harm to the brain), hypoxic ischemic encephalopathy (abnormal neurological function), meconium aspiration syndrome (meconiumstained amniotic fluid (MSAF) and meconium within lungs), hypothermia (temperature below $36.5^{\circ} \mathrm{C}$ ), hypoglycemia (blood glucose $<70$ $\mathrm{mg} / \mathrm{dl}$ ), hypocalcaemia (total serum calcium concentration $<8 \mathrm{mg} / \mathrm{dL}$ in term infants or $<7$ $\mathrm{mg} / \mathrm{dL}$ in preterm infants), thrombocytopenia (platelet count less than $150 \times 10^{\circ} / \mathrm{L}$ ), polycythemia (central venous Hct over $65 \%$ or a hemoglobin value above $22 \mathrm{~g} / \mathrm{dL}$ ) and infections. All relevant investigations along with the demographic data were recorded in proforma.

All the data were analyzed through Statistical Package for Social Sciences (SPSS) version 16. All quantitative variables like age and weight were presented as mean and standard deviation while qualitative variables like gender, maternal factors and neonatal complications were presented as frequency and percentages. Chi square test was applied with 95\% confidence interval \& p-value $\leq 0.05$ was taken as significant.

\section{RESULTS}

There were 157 patients in total. Males were $56.1 \%$ while females were $43.9 \%$. Mean age of the patients was $12.73+6.65$ hours at presentation. Mean weight of the patients was $2.03+0.65 \mathrm{~kg}$. Among the mothers, $61.1 \%$ were nulliparous while $38.9 \%$ were multiparous. Anemia was found to be present in $47.8 \%$ however inter pregnancy intervals was found to be one year in $58.6 \%$ while it was more than one year in $41.4 \%$. 
Out of 157 in $61.8 \%$ hypertension was present. Among the small for gestational age babies, perinatal asphyxia was found to be present in $63.7 \%$, meconium aspiration was present in $51 \%$, hypothermia was found in $37.6 \%$, hypoglycemia was present in $24.2 \%$, hypocalcaemia was present in $32.5 \%$ polycythemia was present in $47.1 \%$, thrombocytopenia was present in $41.4 \%$.

Table-II shows evaluation of maternal risk factors

\begin{tabular}{|l|c|}
\hline \multicolumn{1}{c}{ Total Patients } & 157 \\
\hline Males & $88 / 157(56.1 \%)$ \\
\hline Females & $69 / 157(43.9 \%)$ \\
\hline Mean age (hours) & $12.73+6.65$ \\
\hline Mean weight & $2.03+0.65$ \\
\hline Nulliparous & $96 / 157(61.1 \%)$ \\
\hline Multiparous & $61 / 157(38.9 \%)$ \\
\hline Anemia in mothers & $75 / 157(47.8 \%)$ \\
\hline Inter pregnancy interval one year & $92 / 157(58.6 \%)$ \\
\hline Inter pregnancy interval more than one year & $65 / 157(41.4 \%)$ \\
\hline Hypertension in mothers & $97 / 157(61.8 \%)$ \\
\hline Perinatal asphyxia & $100 / 157(63.7 \%)$ \\
\hline Meconium aspiration & $80 / 157(51 \%)$ \\
\hline Hypothermia & $59 / 157(37.6 \%)$ \\
\hline Hypoglycemia & $38 / 157(24.2 \%)$ \\
\hline Hypocalcaemia & $51 / 157(32.5 \%)$ \\
\hline Polycythemia & $74 / 157(47.1 \%)$ \\
\hline Thrombocytopenia & $65 / 157(41.4 \%)$ \\
\hline
\end{tabular}

Table-I. Characteristic of Patients.

\begin{tabular}{|c|c|c|c|}
\hline Maternal Risk Factors & Males & Females & P-Value \\
\hline Nulliparous & $57 / 88(64.8 \%)$ & $39 / 69(56.5 \%)$ & \multirow{2}{*}{0.325} \\
\hline Multiparous & $31 / 88(35.2 \%)$ & $30 / 69(43.5 \%)$ & \\
\hline Anemia in mothers & $43 / 88(48.9 \%)$ & $32 / 69(46.4 \%)$ & 0.872 \\
\hline Inter pregnancy interval one year & $45 / 88(51.1 \%)$ & $47 / 69(68.1 \%)$ & 0.035 \\
\hline Inter pregnancy interval more than one year & $43 / 88(48.9 \%)$ & $22 / 69(31.9 \%)$ & 0.411 \\
\hline Hypertension in mothers & $57 / 88(64.8 \%)$ & $40 / 69(58 \%)$ & 0.098 \\
\hline \multicolumn{4}{|c|}{ Neonatal Complications } \\
\hline Perinatal asphyxia & $51 / 88(58 \%)$ & $49 / 69(71 \%)$ & 0.098 \\
\hline Meconium aspiration & $44 / 88(50 \%)$ & $36 / 69(52.2 \%)$ & 0.872 \\
\hline Hypothermia & $33 / 88(37.5 \%)$ & 26/69 (37.7\%) & 0.999 \\
\hline Hypoglycemia & $21 / 88(23.9 \%)$ & $17 / 69(24.6 \%)$ & 0.999 \\
\hline Hypocalcaemia & $28 / 88(31.8 \%)$ & $23 / 69(33.3 \%)$ & 0.865 \\
\hline Polycythemia & $34 / 88$ (38.6\%) & 22/69 (31.9\%) & 0.406 \\
\hline Thrombocytopenia & $35 / 88$ (39.8\%) & $30 / 69(43.5 \%)$ & 0.744 \\
\hline
\end{tabular}

Table-II. Maternal risk factors \& neonatal complications with respect to gender. 


\begin{tabular}{|c|c|c|c|}
\hline Maternal Risk Factors & Weight $<2$ kg & Weight $>2$ kg & P-Value \\
\hline Nulliparous & $48 / 81(59.3 \%)$ & 48/76 (63.2\%) & \multirow{2}{*}{0.101} \\
\hline Multiparous & $33 / 81(40.7 \%)$ & $28 / 76(36.8 \%)$ & \\
\hline Inter pregnancy interval one year & $48 / 81(59.3 \%)$ & $44 / 76(57.9 \%)$ & \multirow{2}{*}{0.742} \\
\hline Inter pregnancy interval more than one year & $33 / 81(40.7 \%)$ & $32 / 76(42.1 \%)$ & \\
\hline \multicolumn{4}{|c|}{ Neonatal Complications } \\
\hline Perinatal asphyxia & $50 / 81(61.7 \%)$ & $50 / 76(65.8 \%)$ & 0.410 \\
\hline Meconium aspiration & 43/81 (53.1\%) & $37 / 76(48.7 \%)$ & 0.294 \\
\hline Hypothermia & 29/81 (35.8\%) & $30 / 76(39.5 \%)$ & 0.101 \\
\hline Thrombocytopenia & $31 / 81(38.3 \%)$ & $34 / 76$ (44.7\%) & 0.450 \\
\hline
\end{tabular}

Table-III. Effect of weight on the frequency of various maternal risk factors and neonatal complications.

\section{DISCUSSION}

Small-for-gestational-age (SGA) babies comprise approximately $50 \%$ of stillbirths, and survivors are at increased risk of cardiovascular disease and diabetes in adulthood. Historically, SGA has most commonly been defined using population birth weight centiles, but the use of customized centiles has enabled the identification of small babies at higher risk of morbidity and mortality than those identified by population centiles.

In the present study, we noted that $61.1 \%$ patients were born to nulliparous mothers. In one study ${ }^{12}$ which assessed the relationship of parity with risk of small for gestational age babies it was found that Nulliparous, age $<18$ year women, compared with women with parity 1-2 and age 18-35 years had the highest odds of SGA (pooled adjusted OR: 1.80), preterm (pooled aOR: 1.52), neonatal mortality (pooled aOR: 2.07), and infant mortality (pooled aOR: 1.49). Increased odds were also noted for SGA and neonatal mortality for nulliparous/age 18-35 years, preterm, neonatal, and infant mortality for parity $\geq 3$ /age $18-<35$ years, and preterm and neonatal mortality for parity $\geq 3 / \geq 35$ years. It was concluded that Nulliparous women $<18$ years of age had the highest odds of adverse neonatal outcomes. Family planning has traditionally been the least successful in addressing young age as a risk factor; a renewed focus must be placed on finding effective interventions that delay age at first birth.

In the present study, $47.8 \%$ babies were having mothers who had anemia. A meta-analysis performed to pool associations, categorized by the hemoglobin cutoffs presented by the authors. ${ }^{13}$ They identified 12 studies reporting associations between maternal anemia and SGA. For the meta-analysis, there were 7 associations with a hemoglobin cutoff $<110 \mathrm{~g} / \mathrm{L}, 7$ with a cutoff $<100$ $\mathrm{g} / \mathrm{L}$, and 5 with a cutoff $<90$ or $<80 \mathrm{~g} / \mathrm{L}$. Although the $<110$ - and $<100-g / L$ categories showed no significant relationship with SGA, the $<90$ - or $<80$ $\mathrm{g} / \mathrm{L}$ category was associated with a $53 \%$ increase in risk of the newborn being SGA [pooled OR = 1.53 (95\% Cl: 1.24-1.87); $\mathrm{P}<0.001]$. Moderate to severe, but not mild, maternal anemia appears to have an association with SGA outcomes, but the findings must be viewed with caution due to the great heterogeneity of the studies. Further examination should be conducted using datasets with better standardized definitions and measurements of exposure and outcome.

In the current study, we noted that $58.6 \%$ babies were born to mothers whose inter pregnancy interval was less than one year. In one ${ }^{14}$ study birth interval of shorter than 18 months had statistically significant increased odds of SGA 
(pooled aOR: 1.51, 95\% Cl: 1.31-1.75), preterm (pooled aOR: 1.58, 95\% Cl: 1.19-2.10) and infant mortality (pooled aOR: 1.83, 95\% Cl: 1.192.81) after controlling for potential confounding factors (reference $36-<60$ months). It was also significantly associated with term-SGA, pretermappropriate-for-gestational-age, and pretermSGA. Birth interval over 60 months had increased risk of SGA (pooled aOR: 1.22, 95\% Cl: $1.07-$ 1.39) and term-SGA (pooled aOR: $1.14,95 \% \mathrm{Cl}$ : 1.03-1.27), but was not associated with other outcomes. It was found that birth intervals shorter than 18 months were significantly associated with SGA, preterm birth and death in the first year of life. Lack of access to family planning interventions thus contributed to the burden of adverse birth outcomes and infant mortality in LMICs.

Few studies to date have examined the effect of severe pre-eclampsia, pre-eclampsia, and gestational hypertension on birth weight according to gestational age. In a population-based retrospective cohort study ${ }^{15}$ of 16,936 pregnant women in Suzhou, China, analysis of variance and multivariable linear regression were performed to compare the mean birth weights of babies born to mothers with gestational hypertension, preeclampsia, and severe pre-eclampsia with birth weights of infants born to mothers with normal blood pressure at each week of gestation. The birth weights were statistically significantly lower in women with severe pre-eclampsia than in women with normal blood pressure for gestational age categories $<$ or $=35$ and 36 weeks. In this Chinese population, most babies born to mothers with severe pre-eclampsia or pre-eclampsia and gestational hypertension had similar fetal growth to those born to normotensive mothers.

In one study among ${ }^{16} 376$ (10.7\%) SGA infants, 281 (74.7\%) were normotensive-SGA and 95 (25.3\%) were hypertensive-SGA. Independent risk factors for normotensive-SGA were low maternal birth weight, low fruit intake pre-pregnancy, cigarette smoking, increasing maternal age, daily vigorous exercise, being a tertiary student, head and abdominal circumference of less than the tenth centile and increasing uterine artery Doppler indices at the 20-week scan.
In another randomized controlled study ${ }^{17}$, all SGA infants studied had a birth weight below the 2.5th percentile in our fetal growth curve and the control infants were matched for gestational age and mode of delivery. In another study ${ }^{18}$, compared with AGA controls, significant $(P<$ .05) maternal risk factors for SGA status included single marital status (59\% versus 53\%), lower pre pregnancy weight (144+/- 41 lbs versus $153+/$ $40 \mathrm{lbs}$ ), lower weight gain during pregnancy (29 +/- 15 lbs versus 33 +/- 15 lbs), smoking (25\% versus $17 \%$ ), hypertension (14\% versus $7 \%$ ), and multiple gestation ( $9 \%$ versus $2 \%$ ).

In our study there were 157 patients in total with a slight predominance of males as $88 / 157$ (56.1\%) while females were 69/157 (43.9\%). Mean age of the patients was $12.73+6.65$ hours at presentation. Mean weight of the patients was $2.03+0.65 \mathrm{Kg}$. Among various maternal risk factors, the hypertension was the most frequently encountered problem seen in 97/157 $(61.8 \%)$ followed by nulliparous which was present in 96/157 (61.1\%). \%). Inter pregnancy interval one year was the next most frequent maternal risk factor found in 92/157 (58.6\%) followed by anemia which was present in 75/157 (47.8\%). Among the small for gestational age babies perinatal asphyxia was found to be the most frequent complication which was present in $100 / 157(63.7 \%)$ followed by Meconium aspiration present in $80 / 157$ (51\%), polycythemia present in $74 / 157(47.1 \%)$, thrombocytopenia in $65 / 157$ (41.4\%), hypothermia in 59/157 (37.6\%). Hypocalcaemia was present in 51/157 (32.5\%) while Hypoglycemia was present in $38 / 157$ (24.2\%).

In the study conducted by Chandra Dey et $\mathrm{al}^{19}$, among 200 SGA cases, 114 were male and 86 were female. All cases were included within 24 hours of age. The anthropometric analysis of the SGA babies showed more than $80 \%$ of the SGA babies were normal in length whereas $19.5 \%$ fell below $10^{\text {th }}$ percentile of normal. Seventy three percent of SGA babies were asymmetrically (disproportionate) and $27 \%$ of babies were symmetrically (proportionate) growth retarded. The main problems associated with the SGA 
babies were perinatal asphyxia (65.5\%), sepsis (54\%), jaundice (42.0\%), hypothermia (31\%), apnea (29\%), hypoglycemia (25\%), and bleeding manifestations (9\%).

\section{CONCLUSION}

Maternal hypertension, null parity, short inter pregnancy interval and anemia are all frequently encountered risk factors for small for gestational age babies in our patient population and these patients should be closely followed up with frequent antenatal visits and specialized peri-partum facilities to avoid the perinatal complications in the newborns. The most frequently encountered perinatal complications observed in our population of small for gestational age babies include perinatal asphyxia, meconium aspiration, polycythemia, thrombocytopenia, hypothermia, hypocalcaemia and hypoglycemia in decreasing order of frequency.

\section{Copyright@ 03 July, 2019.}

\section{REFERENCES}

1. Malhotra A, Allison BJ, Castillo-Melendez M, Jenkin G, Polglase GR, Miller SL. Neonatal morbidities of fetal growth restriction: Pathophysiology and impact. Frontier in Endocrinology 2019; 10:55.

2. Mohammad N, Sohaila A, Rabbani U, Ahmed S, Ahmed S, Ali SR. Maternal predictors of intrauterine growth retardation. J Coll Physicians Surg Pak. 2018 Sep; 28(9):681-685.

3. Lubcheno L, Hansman C, Dressler M, Body E. Intrauterine growth as estimated from live born birth weight data at 24 to $\mathbf{4 2}$ weeks gestation. Pediatrics. 1963; 32:793-800.

4. Maqbool S, Hodge W. Small for gestational age infants. In: Maqbool S, Hodge W. Handbook of neonatal care. Lahore: Nabiza, 1996:49-56.

5. Ahmad A, Ahmad TM, Akram DS, Arif MA, Ashraf RN, Aziz K, et al. Low birth weight babies. In: Haneef SM, Maqbool S, Arif MA. Text book of paeditrics PPA. Lahore: International book bank, 2000:189.

6. Hailu LD, Kebede DL. Determinants of low birth weight among deliveries at a referral hospital in Northern Ethiopia. Bio Med Research International 2018; 2:1-8.

7. Rehan N. Nutritional deficiencies in Pakistani women. Mothers and child. 1999; 37:118
8. Thinker AG. Improving women's health in Pakistan. J Coll Physicians Surg Pakistan. 1999; 9:66-9.

9. Jackson K, Harrington JW. In Brief SGA and VLBW Infants: Outcomes and care. Pediatrics in Review 2018; 39(7):375-7.

10. Ludvigsson JF, Lu D, Hammarstrom L, Cnattingius $S$, Fang F. Small for gestational age and risk of childhood mortality: A Swedish population study. PLo S Med 2018; 15(12): e1002717.

11. Park K. Low birth weight. In: Park K. Park's textbook of preventive and social medicine. $23^{\text {rd }} \mathrm{ed}$. India: Banarsidas Bhanot, 2002:354-5.

12. Kozuki N, Lee A, Silveira MF, Sania A, Vogel JP, Adair L, et al. The associations of parity and maternal age with small-for-gestational-age, preterm, and neonatal and infant mortality: A meta-analysis. BMC Public Health. 2013; 13:11-6.

13. Kozuki N, Lee AC, Katz J. Moderate to severe, but not mild, maternal anemia is associated with increased risk of small-for-gestational-age outcomes. J Nutr. 2012; 142(2):358-62.

14. Kozuki1 N, Lee AC, Silveira MF, Victora CG, Adair L, Humphrey J. The associations of birth intervals with small-for-gestational-age, preterm, and neonatal and infant mortality: A meta-analysis. BMC Public Health. 2013; 13:3-9.

15. Xiong $X$, Fraser WD. Impact of pregnancy-induced hypertension on birth weight by gestational age. Paediatr Perinat Epidemiol. 2004 May; 18(3):186-91.

16. Mc Cowan LME, Roberts CT, Dekker GA, Taylor RS, Chan EHY, Kenny LC. Risk factors for small-forgestational-age infants by customized birth weight centiles: Data from an international prospective cohort study. BJOG. 2010; 21:1-7.

17. Tenovuo A. Neonatal complications in small-forgestational age neonates. J Perinat Med. 1988; 16(3):197-203.

18. Doctor BA, O'Riordan MA, Kirchner HL, Shah D, Hack M. Perinatal correlates and neonatal outcomes of small for gestational age infants born at term gestation. Am J Obstet Gynecol. 2001 Sep; 185(3):652-9.

19. Chandra dey A, Ahmed F, Mannan A, Saha L, Barua CC, Mahmood CB. Small for gestational age babies: Morbidity and immediate outcome in a Tertiary Care Hospital - A prospective Study. Bangladesh Journal of Child Health. 2007; 31:1-3. 


\begin{tabular}{|c|l|l|l|}
\multicolumn{3}{|c|}{ AUTHORSHIP AND CONTRIBUTION DECLARATION } \\
\hline Sr. \# & \multicolumn{1}{|c|}{ Author(s) Full Name } & \multicolumn{1}{|c|}{ Contribution to the paper } & Author(s) Signature \\
\hline 1 & Saima Jabeen Joiya & $\begin{array}{l}\text { Methodology, Data collection, } \\
\text { Review of literature. } \\
\text { Supervision, Methodology, } \\
\text { Discussion. } \\
\text { Data analysis, Drafting. }\end{array}$ \\
\hline 2 & M. Azam Khan & Zahid Ahmad & \\
\hline
\end{tabular}

